\title{
Surface Evaluation of Photoactivated TiO2 Films
}

R. M. Woo-Garcia ${ }^{1}$, L. García-González ${ }^{1}$, A. L. Herrera-May ${ }^{1}$, C. Zuñiga-Islas², W, CallejaArriaga $^{3}$, J. Molina-Reyes ${ }^{2}$, M. Pacio-Castillo ${ }^{3}$ and F. López-Huerta, ${ }^{4, *}$

${ }^{1}$ Micro and Nanotechnology Research Center, Universidad Veracruzana, Adolfo Ruiz Cortines 455, Veracruz, Mexico

${ }^{2}$ National Institute of Astrophysics, Optics and Electronics, Luis Enrique Erro 1, Puebla, Mexico

${ }^{3}$ Research Center on Semiconductor Devices, Benemérita Universidad Autónoma de Puebla, Adolfo Ruiz Cortines 455, Puebla, Mexico

${ }^{4}$ Faculty of Electrical and Electronic Engineering, Universidad Veracruzana, Adolfo Ruiz Cortines 455, Veracruz, Mexico

*Email: frlopez@uv.mx

In recent years, the applications of titanium dioxide $\left(\mathrm{TiO}_{2}\right)$ films include water and medical treatment [1]. These applications depend on the following characteristics of the $\mathrm{TiO}_{2}$ films: specific surface area, crystal and grain size, concentration and dopant. $\mathrm{TiO}_{2}$ films can be synthesized through different methods and used to produce biosensors due to their high biocompatibility [2-3]. We present the morphology of $\mathrm{TiO}_{2}$ films, deposited on a quartz substrate at room temperature by DC magnetron sputtering using a titanium target with a diameter of $50.8 \mathrm{~mm}$. A $\mathrm{TiO}_{2}$ ceramic material covers $20 \%$ of the titanium target surface. The quartz substrate is cleaned in an ultrasonic bath of acetone $\left(\mathrm{C}_{3} \mathrm{H}_{6} \mathrm{O}\right)$, ethanol $\left(\mathrm{C}_{2} \mathrm{H}_{6} \mathrm{O}\right)$ and distilled water for 5 minutes at room temperature. The deposition is made under an Argon (Ar) atmosphere and a chamber pressure of $7.46 \mathrm{E}-6$ mbar. The $\mathrm{TiO}_{2}$ films are postdeposition annealed at different temperatures $\left(300,500\right.$ and $\left.800{ }^{\circ} \mathrm{C}\right)$. The films are treated with ultraviolet light (UV) for 15 minutes at room temperature to photoactivate the surface. To characterize the topography of the $\mathrm{TiO}_{2}$ films, the samples are analyzed by atomic force microscopy (AFM) in a non-contact mode and processed using Gwyddion software. The AFM technique showed the transition of anatase to rutile phase. Figure 1 shows typical topography three-dimensional (3D) images $(1 \mu \mathrm{m} \times 1 \mu \mathrm{m}$ scan area) of TiO2 films annealed at different temperatures. Table I showed the measured root-mean-square (RMS) surface roughness changes from $2.28 \mathrm{~nm}$ to $7.18 \mathrm{~nm}$ when treated with UV, this change causes a greater affinity with neuronal cells.

\section{References}

[1] J. Molina-Reyes, et al., Catalysis Today (2018).

[2] F.Lopez-Huerta, et al., Materials. 7 (2014) 4088-4100.

[3] B. Cervantes, et al., Materials. 9 (2016) 1-11.

Table 1. Average values of the crystalline grain size of $\mathrm{TiO} 2$ films annealed at different temperatures. Heat Treatment $\left({ }^{\circ} \mathrm{C}\right) \quad$ RMS (nm) with UV RMS (nm) without UV

\begin{tabular}{|l|l|l|}
\hline & & \\
\hline 300 & 7.18 & 2.28 \\
\hline 500 & 4.92 & 1.38 \\
\hline 800 & 5.47 & 2.36 \\
\hline
\end{tabular}



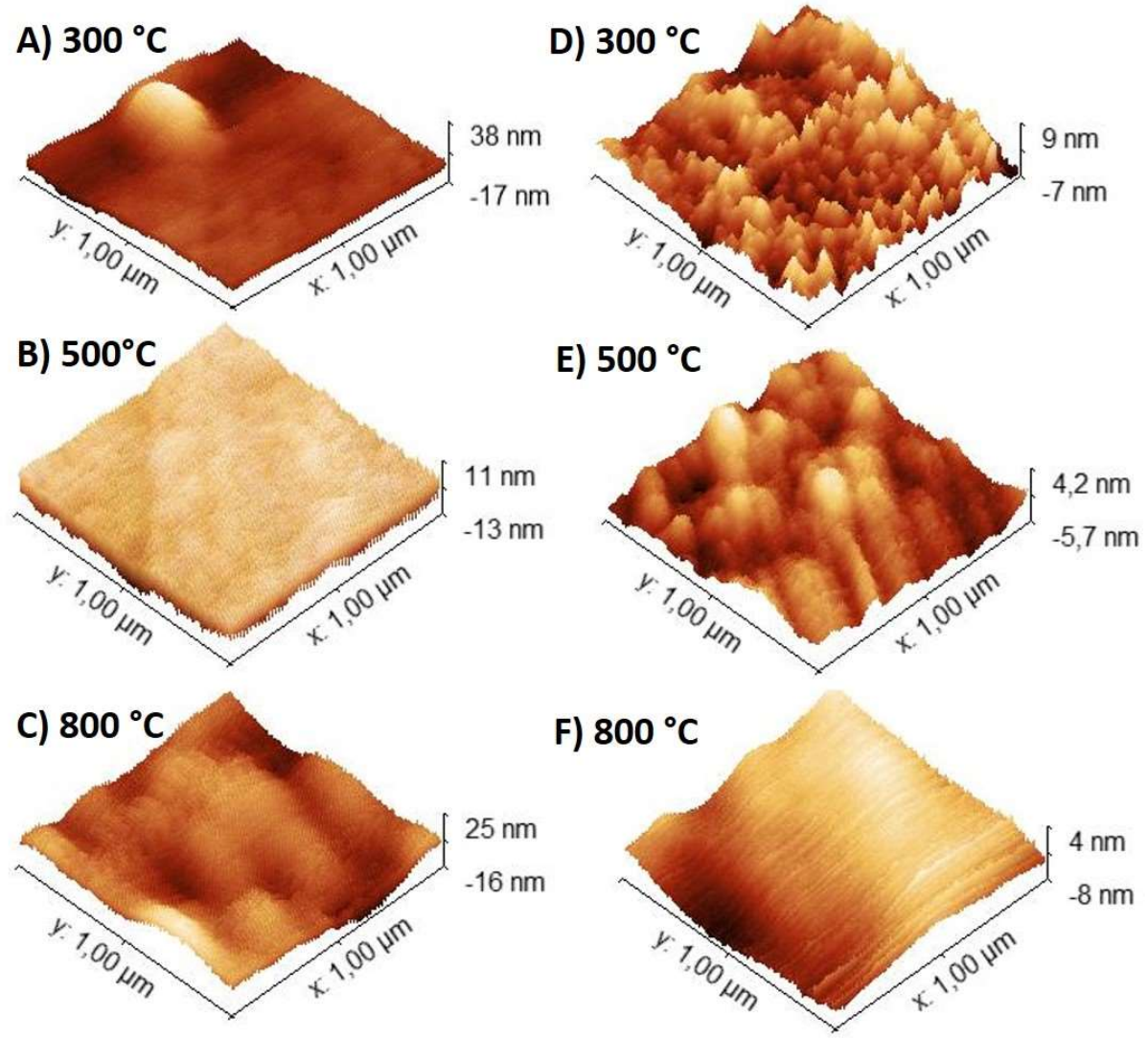

Figure 1. AFM images of the surface of $\mathrm{TiO}_{2}$ films annealed at different temperatures: A-C) with UV, D-F without UV. 